\title{
Head and Neck Cancers Case Control Study of HIV Positive Compared to Negative Patients in a Ugandan Population Sample
}

\author{
Kamulegeya Adriane ${ }^{1}$, Otiti Jeff ${ }^{2}$ \\ ${ }^{1}$ Department of Dentistry, Makerere University, Kampala, Uganda \\ ${ }^{2}$ Department of Surgery, Uganda Cancer Institute, Kampala, Uganda
}

Email address:

adrianek55@gmail.com (K. Adriane)

To cite this article:

Kamulegeya Adriane, Otiti Jeff. Head and Neck Cancers Case Control Study of HIV Positive Compared to Negative Patients in a Ugandan Population Sample. International Journal of Clinical Oral and Maxillofacial Surgery. Vol. 3, No. 4, 2017, pp. 20-25. doi: 10.11648/j.ijcoms.20170304.11

Received: October 23, 2017; Accepted: November 13, 2017; Published: December 21, 2017

\begin{abstract}
Increased availability of highly active anti-retroviral therapy (HAART) has led to a change in the spectrum of neoplastic diseases affecting people living with HIV. Some cancers such as invasive cervical carcinoma and anal cancers have not changed or instead risen while others such as Kaporsi's sarcoma have seen a sharp decline. The aim of this study was to compare clinical findings at presentation between HIV positive and Negative patients with head and neck cancers using a retrospective case control design. The study was done at the Uganda cancer Institute by performing a manual match of records in the head and neck cancer database at a ratio of 1:2 cases: controls. The matching was done on the age group, gender and diagnosis. Clinical and demographic characteristics between HIV positive and HIV negative head and neck cancer patients were compared using chi square and a multinomial model including ECOG performance score, stage, grade and duration group was run. In the multinomial regression only duration group was significant with the HIV positive patients being more likely to present after a longer duration of the symptoms than HIV negative patients ( $\mathrm{OR}=0.42 \mathrm{CI} 0.20-0.86 \mathrm{p}=0.02)$. The data does not show statistically significant difference between HIV positive and HIV negative head and neck cancer patients in terms of presentation at time of diagnosis except for duration of symptoms group. This study clearly demonstrates the need for more research on head and neck cancer in Africa in the context of HIV/AIDS, since the reasons for the high HIV prevalence among this cohort of patients hasn't been established.
\end{abstract}

Keywords: Head and Neck Cancers, HIV/AIDS, Cancer Risk Factors

\section{Introduction}

Since the time HIV/AIDS, was recognized by the medical fraternity, a number of other disease entities have been associated with the syndrome. Those that have been labeled as opportunistic such as (candidaiasis, herpes zoster) were due to depressed immunity and before the HAART era potented death [1]. On the other hand neoplastic diseases such as Sarcoma of Kaposi (KS) and primary central nervous system non-Hodgkin's lymphomas (PCNLs) are considered as illness defining while other NHLs such as Burkitt's (BL), diffuse large $\mathrm{B}$ cell (DLBCL) and primary effusion lymphomas (PEL) have an increased incidence among $\mathrm{HIV}+\mathrm{ve}$ people. Invasive cervical and anal carcinomas have also been noted to increase among people living with HIV [2].

However, with the increased availability of highly active anti-retroviral therapy (HAART) the spectrum of neoplastic diseases affecting people living with HIV has changed tremendously with a sharp decline in KS, DLBCL, PEL and epidemic associated BL. Though some such as invasive cervical carcinoma and anal cancers have not changed or have instead risen [3]. Another development is the fact that as people living with HIV have longer life spans with the disease, thus increasingly we are seeing them with other non AIDS defining cancers [4], [5]. In Uganda HIV/AIDS associated malignancies such as $\mathrm{KS}$, NHL and invasive SCCA of the cervix have been shown to rise but the 
increased roll out of HAART should also have an effect on their incidence [6].

It's estimated that by the year 2030 approximately a million people will be dying from cancer related causes on the African continent [7]. Head and neck cancers being among the top ten cancers worldwide are important enough to look at in the context of HIV AIDS. Additionally developing countries especially those in Sub Saharan Africa not only bare the blunt of HIV/AIDS, but also increasingly have a high incidence of cancers [8], [9], [10], [11]. A study from Uganda showed nasopharyngeal carcinoma (a head and neck cancer) as one of the non AIDS associated cancers with increased incidence presenting at late stages after diagnosis [6]. Head and neck cancers have been reported to have increased incidence among people living with HIV/AIDS and are thought to be associated with viral infections such as HPV and EBV [12]. Since demonstration of increased HPV sero prevalence has been reported among $\mathrm{HIV}+$ patients [13], [14], Its plausible that head and neck cancers associated with HPV and other viruses would increase and maybe behave differently among people living with HIV hence our interest in seeing differences and similarities at presentation of HIV positive head and neck cancer patients compared to the negative ones.

\section{Methodology}

\subsection{Materials and Methods}

The Uganda Cancer Institute is a six hundred bed hospital that serves as the main referral cancer center in Uganda. The institute is supposed to have oncology chemotherapy and radiotherapy as well as some surgical capacity. As of now the radiotherapy machine is down but being worked on. Every Tuesday the head and neck tumor board sits to discuss all new fully staged patients referred to the institute with a head and neck cancer diagnosis except for lymphomas that are sent to the lymphoma treatment center (LTC) of the same institute. Also patients who need a joint consultation given the progress of the treatment for their cancers are referred back for discussion. During the tumor board we capture details of the patients in an excel database which we update whenever missing results are got or if we see the patient again for any reason. We performed a manual match of records in this cancer database. The matching was 1:2 cases: controls. We matched on the age group, gender and diagnosis. The age group was 5 year range such as $0-5,5-10$ years while diagnosis we just matched on histological diagnosis for example squamous cell carcinoma, rhabdomyosarcoma. Only de- identified data were retained by the investigators $i$. e. the hospital numbers were deleted from the extracted data. The current study was restricted to cases from the most recent head and neck tumor board meetings 2014-March 2017. Cancer treatment and results data was only available in a few cases in this cancer database but when available was included in the information captured. Institutional review boards at the School of Health Sciences Makerere University exempted the study from seeking patient consent.

We selected all patients with a diagnosis of head and neck cancer excluding Kaporsi's sarcoma, lymphomas and thyroid cancers that went through the head and neck tumor board at UCI during 2014-march 2017. HIV status was determined through either patient reported sero status for those who were in treatment and a routine counseling and testing result for all others who were not in HIV care or reported negative results. A total of 394 head and neck cancer cases were discussed during 2014-end of March 2017 tumor board meetings of which $59(15 \%)$ cases were HIV positive.

Head and neck cancer stage (local, regional, distant, or unknown) was constituted by taking into consideration the tumor size (either by clinical examination or CT scan reports), nodal involvement, chest $\mathrm{x}$-ray and abdominal ultra sound. The staging was based on the WHO TNM cancer staging and a similar staging system for the sarcomas was used [15], [16].

\subsection{Statistical Analysis}

We compared clinical and demographic characteristics between HIV positive and HIV negative head and neck cancer patients using chi square and binary logistic regression. Multinomial model included ECOG performance score, stage, grade, duration group.

\section{Results}

Table 1 presents characteristics of the HIV-infected and HIV-uninfected matched head and neck cancer patients $\mathrm{N}=$ 59 and $\mathrm{N}=118$, (a ratio of 1:2 respectively). Given the fact that we matched on age, HIV-uninfected patients and HIVinfected patients were of same age at diagnosis (median age $46 \pm 13.7$ vs. $48 \pm 13.5$ years), males constituted the majority of patients at $62.7 \%$. The HIV+ positive compared to the negative patients combined use of alcohol and tobacco were $57.6 \%, 42.4 \%$ compared to $52.5 \%, 47.5 \%$ never user versus ever users respectively.

Additionally, HIV-infected patients and HIV-uninfected patients didn't have statistically significant difference in terms of agreement between the histological diagnosis and clinical assessment of the board (Table 1).

Likewise there was no difference in mean hemoglobin concentration between HIV positive and HIV negative patients $(\mathrm{P}=0.34 \mathrm{p}=0.14)$ respectively.

The distribution of anatomical sites in relationship to the diagnosis and sero-status are shown in Figure 1.

Binary logistic regression comparing HIV negative and HIV positive didn't not yield any significant findings; Ecog OR 0.75 CI 0.51 - 1.09, Grade OR 0.95 CI 0.62 - 1.46, Stage OR 1.03 CI $0.68-1.57$, Duration OR 1.02 CI $0.99-1.03$.

In the multinomial regression only duration group was significant with the HIV positive patients being more likely to present after a longer duration of the symptoms than HIV negative patients $(\mathrm{OR}=0.42 \mathrm{CI} 0.20-0.86 \mathrm{p}=0.02)$. 
Table 1. Shows the clinical features of the patients.

\begin{tabular}{|c|c|c|c|c|c|}
\hline Clinical features & & $\mathrm{HIV}+\mathrm{Ve}$ & HIV -Ve & P Value & Chi \\
\hline Median Age & & $46 \pm 13.7$ & $48 \pm 13.5$ & 0.35 & \\
\hline \multirow{4}{*}{ Gender } & $\mathrm{F}$ & 22 & 44 & \multirow{4}{*}{1.00} & \multirow{4}{*}{0.00} \\
\hline & M & 37 & 74 & & \\
\hline & SCCA & 51 & 101 & & \\
\hline & $\mathrm{ACC}$ & 0 & 1 & & \\
\hline \multirow[t]{5}{*}{ Diagnosis } & ADCCA & 2 & 6 & \multirow[t]{5}{*}{0.89} & \multirow[t]{5}{*}{0.18} \\
\hline & ANCA & 3 & 7 & & \\
\hline & Sarcomas & 2 & 4 & & \\
\hline & Never & 34 & 62 & & \\
\hline & Smoker & 19 & 30 & & \\
\hline \multirow[t]{3}{*}{ Smoking Alcohol use } & Alcohol & 5 & 5 & \multirow[t]{3}{*}{0.19} & \multirow[t]{3}{*}{1.72} \\
\hline & Smoker and alcohol use & 1 & 20 & & \\
\hline & Not specified & 0 & 1 & & \\
\hline \multirow{2}{*}{ Duration of symptoms } & Early & 8 & 27 & \multirow{2}{*}{0.09} & \multirow{2}{*}{2.73} \\
\hline & late & 44 & 73 & & \\
\hline \multirow{2}{*}{ Stage group } & Early & 7 & 10 & \multirow{2}{*}{0.47} & \multirow{2}{*}{0.51} \\
\hline & Late & 52 & 108 & & \\
\hline \multirow{5}{*}{ T stage } & $\mathrm{T} 1$ & 2 & 5 & \multirow{5}{*}{0.42} & \multirow{5}{*}{0.63} \\
\hline & $\mathrm{T} 2$ & 9 & 8 & & \\
\hline & $\mathrm{T} 3$ & 10 & 25 & & \\
\hline & $\mathrm{T} 4$ & 38 & 74 & & \\
\hline & Tx & 0 & 2 & & \\
\hline \multirow{4}{*}{ Nodal status } & No & 9 & 33 & \multirow{4}{*}{0.69} & \multirow{4}{*}{0.15} \\
\hline & N1 & 18 & 25 & & \\
\hline & $\mathrm{N} 2$ & 18 & 26 & & \\
\hline & N3 & 14 & 34 & & \\
\hline \multirow{4}{*}{ Grade } & 1 & 54 & 109 & \multirow{4}{*}{0.83} & \multirow{4}{*}{0.04} \\
\hline & 2 & 1 & 1 & & \\
\hline & 3 & 0 & 2 & & \\
\hline & 4 & 4 & 6 & & \\
\hline \multirow{4}{*}{ ECOG } & 0 & 12 & 36 & \multirow{4}{*}{0.772} & \multirow{4}{*}{2.14} \\
\hline & 1 & 27 & 50 & & \\
\hline & 2 & 17 & 29 & & \\
\hline & 3 & 3 & 3 & & \\
\hline Metastasis & yes & 9 & 14 & 0.53 & 0.39 \\
\hline Mivtastasis & no & 50 & 104 & & \\
\hline A oreement with initial histolooic al findinoc & Yes & 14 & 13 & 006 & 338 \\
\hline Agreement with initial histological findings & No & 44 & 102 & 0.00 & 3.08 \\
\hline
\end{tabular}

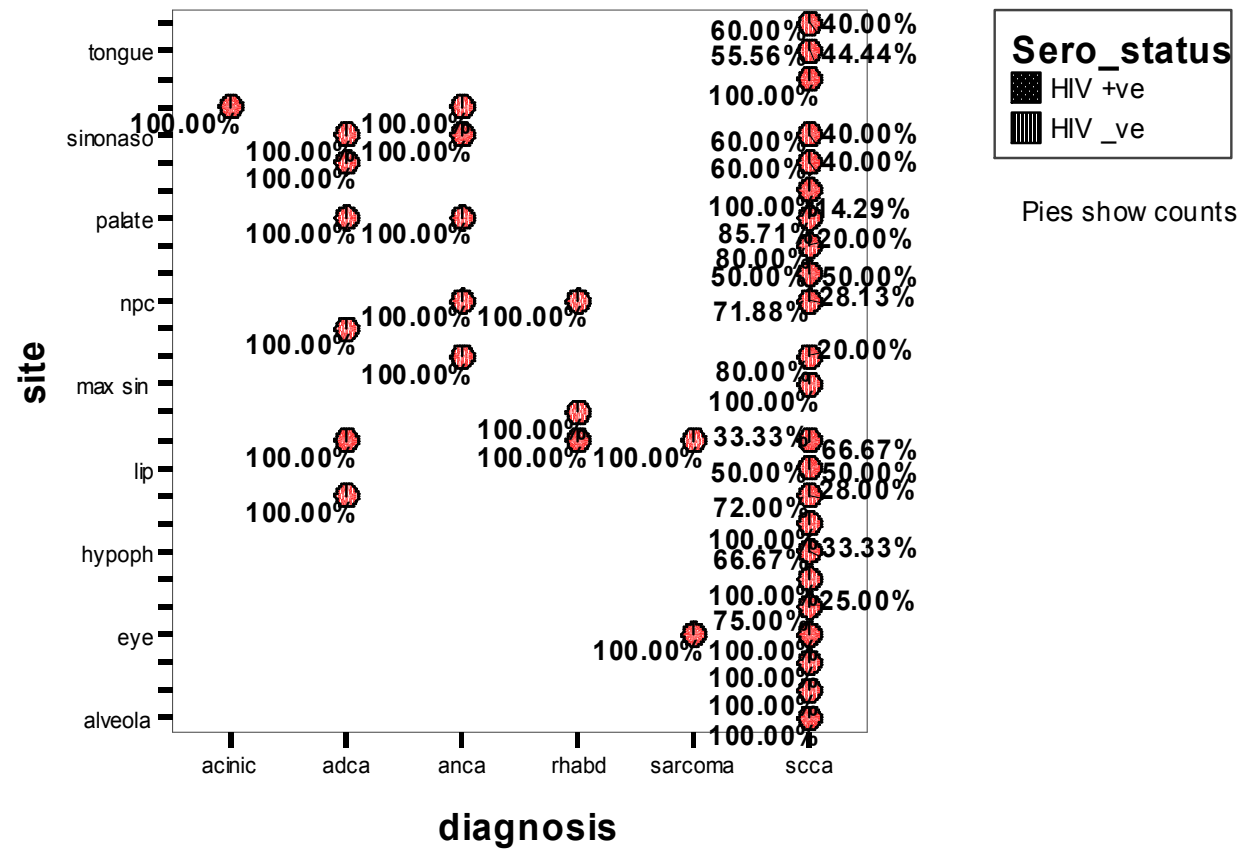

Figure 1. Shows the anatomical and hsitopathological distribution of the cancers against the HIV sero status. 
Table 2. Shows the distributions of head and neck cancer patients as per age groups.

\begin{tabular}{llll}
\hline Age group & HIV +ve (\%) & HIV-ve (\%) & Total (\%) \\
\hline $11-20$ & $1(1.7)$ & $3(2.5)$ & $4(2.3)$ \\
$21-30$ & $8(13.6)$ & $17(14.4)$ & $25(14.1)$ \\
$31-40$ & $14(23.7)$ & $21(17.8)$ & $35(19.8)$ \\
$41-50$ & $14(23.7)$ & $28(23.7)$ & $42(23.7)$ \\
$51-60$ & $15(25.4)$ & $36(30.5)$ & $51(28.8)$ \\
$61-70$ & $5(8.5)$ & $19(16.1)$ & $14(7.9)$ \\
$71-80$ & $2(3.4)$ & $4(3.4)$ & $6(3.4)$ \\
Total & $59(100)$ & $118(100)$ & $177(100)$ \\
\hline
\end{tabular}

\section{Discussion}

Although Head and Neck cancer are not among the most common cancers worldwide, it has been reported that about two thirds are in developing countries [17]. These cancers other than presenting quite late, they cause a lot of morbidity and mortality in these ill equipped countries [18], [19]. Sub Saharan African countries being part of the developing countries are further devastated by a high prevalence of HIV [20]. Some studies have shown an increased prevalence of some head and neck cancers among people living with HIV and as such we need to keep looking at the disease to see any change in trend [12]. Reports combining head and neck cancers and HIV status from Africa are very limited. A case control study on cancers among HIV positive compared to HIV negative patients from Uganda only picked 9 oral and nasal cavity cancers that were grouped under others [6]. Another from Kenya looking at head and neck cancer also picked only 9 cases of squamous cell carcinoma the rest being lymphomas and Kaposi's sarcoma [21]. Therefore a focused look at head and neck cancers in relation to HIV status is still relevant and given the disease's nature, we felt a case control study like this is likely to shade some more light.

As per our data HIV prevalence in this patient population stood at $15 \%$. This prevalence of HIV infection found in our study was double the national prevalence of $7.3 \%$ [22]. This was against the fact that the 51-60 year age group formed the majority of the cases. The national prevalence of HIV infection in that age group is much lower than $15 \%$ [23]. In this study as seen from table 2 , the $51-60$ year age group dominated our patient population followed by $41-50$ group. These are not the groups with highest HIV prevalence. In fact the prevalence in this group should be lower as per the AIDS survey 2011 [24] we therefore should have expected a lower prevalence than we have in our study population. It's not possible for us to point out the potential role of HIV in head and neck cancer patients but the high prevalence warrants more research. This is even more so given that some studies have reported an increase in head and neck cancers among people living with HIV/AIDS [12].

In this study, $51(28.8 \%)$ of the total cases were 51-60 years of age, followed by $40-50$ year age group at $23.7 \%$. This is similar to an earlier study done in Uganda so no change in age distribution [25]. As expected due to matching on age and gender, there was neither statistically significant difference between male and female distribution nor between HIV positive and negative patients as per age groups $(\mathrm{P}=0.09$ $\chi^{2} \quad 10.7$ df 6) ( $p=0.97 \quad \chi^{2}=1.23$ df 6$)$ respectively. The combined male to female ratio was $1.7: 1$ in contrast with 1.3:1 in an earlier study [25] but close to what was reported from Egypt [26]. However, the ratio is lower than what has been reported from most developed countries [27]. This is most likely not due to population distribution since the country has more females than males as age increases [28]. In addition women in Uganda have been reported to have better health seeking behavior than males especially when it comes to using public health facilities [29]. Thus it's very likely that the exposure to risk factors and hence incidence of disease among males is higher than in females.

More than half of the patients $(54.2 \%)$ claimed never to have used tobacco and its products nor taken alcohol and there was no statistically significant difference between HIV positive and negative patients in terms of usage of these risk factors as shown in table 1. Smoking and alcohol intake are known cancer risk factors but in our case there's a high possibility of other associations such as infections, poor nutrition, poor oral hygiene and other herbal concoctions being important factors in causation of cancer [30], [31], [32]. Although there was no difference in tobacco use between HIV positive and negative patients, it's worth noting that a study done in Uganda earlier showed twice the level of tobacco use among HIV patients who were being initiated on HAART than the background population [33].

It's also notable that sometimes information on smoking and alcohol use at the time of diagnosis may not be so accurate due to behavioral modification at onset of disease. Additionally, patients may not be fully truthful about their indulgence in known risk factors due to self blame and avoidance of being blamed for their disease [34]. Furthermore, the type and duration of exposure to these risk factors are more often than not well evaluated. Tobacco products in developing countries are usually homemade with a variety of concoctions whose contents and carcinogenicity may not be known. This can be extrapolated from high cotinine levels among people who reported negative history of tobacco use [33]. Alcohol is also made from different raw materials as per regionally available ingredients and sometimes distilled in crude ways to different concentrations and poisonous contents [35] thus the risk of cancer causation may even be higher from the crude and semi processed products consumed by most of our source population.

Our data does not show statistically significant difference between HIV positive and HIV negative head and neck cancer patients in terms of presentation at time of diagnosis except for duration of symptoms group. This was against the fact that $56 \%$ of our patients were under HIV care. Delay in seeking care by HIV patients as shown by the duration of symptoms has also been noted in a Ugandan study that compared HIV positive and HIV negative patients [36].

Unfortunately we could not add survival data due to lack of a radiotherapy facilities and incessant chemotherapeutic 
medication stock outs. Many of the patients do not get the board prescribed treatment approach. However, our study clearly demonstrates the need for more research on head and neck cancer in Africa in the context of HIV/AIDS, as neither the reasons for the high HIV prevalence among this cohort of patients nor the prognosis and survival difference or similarities have been established.

\section{Conclusion}

Our study clearly demonstrates the need for more research on head and neck cancer in Africa in the context of HIV/AIDS, since the reasons for the high HIV prevalence among this cohort of patients hasn't been established.

\section{Acknowledgements}

The Principal Investigator NURTURE Prof Nelson Sewankambo, Mentors under the same grant Prof Harriet K Mayanja, Assoc Prof Damalie Nakanjjako and Dr Jackson Orem for their continued support, mentorship and encouragement in making us more proficient at research and communicating our findings.

\section{Fund Support}

Adriane Kamulegeya is supported under NURTURE a D43 grant, grant number D43TW010132

\section{References}

[1] K. Djawe, K. Buchacz, L. Hsu, M. Chen, R. M. Selik, C. Rose, T. Williams, J. T. Brooks, and S. Schwarcz, "Mortality Risk After AIDS-De fi ning Opportunistic Illness Among HIV-Infected Persons San Francisco 1981-2012,” J. Infect. Dis., vol. 212, pp. 1366-75, 2015.

[2] M. Bower, A. Palfreeman, M. Alfa-Wali, C. Bunker, F. Burns, D. Churchhill, S. Collins, K. Cwynarski, S. Edwards, P. Fields, and K. Fife, "British HIV Association guidelines for HIV-associated malignancies 2014 British HIV Association guidelines for HIV-associated malignancies 2014," HIV Med., vol. 15, no. Suppl. 2, pp. 1-92, 2014.

[3] M. R. Pinzone, F. Florica, M. Di Rosa, G. Malaguarnera, L. Malaguarnera, B. Cacopardo, G. Zanghi, and G. Nunnari, "Non-AIDS-defining cancers among HIV-infected people," Eur. Med. Pharmacol. Sci., vol. 16, pp. 1377-1388, 2012.

[4] J. F. Deeken, A. Tjen-a-looi, M. A. Rudek, C. Okuliar, M. Young, R. F. Little, and B. J. Dezube, "The Rising Challenge of Non - AIDS-Defining Cancers in HIV-Infected Patients," Clin. Infect. Dis., vol. 55, no. 9, pp. 1228-1235, 2012.

[5] R. T. Mitsuyasu, "Non-AIDS-Defining Malignancies in HIV," Top HIV Med, vol. 16, no. 4, pp. 117-121, 2008.

[6] R. Newton, J. Ziegler, V. Beral, E. Mbidde, L. Carpenter, H. Wabinga, S. Mbulaiteye, P. Appleby, G. Reeves, and H. Jaffe, "A case-control study of human immunodeficiency virus infection and cancer in adults and children residing in Kampala, Uganda.," Int. J. Cancer, vol. 92, no. 5, pp. 622-7, Jun. 2001.
[7] B. S. Sylla and C. P. Wild, "cancer research and control offer to the continent?," Int J Cancer, vol. 130, pp. 245-250, 2012.

[8] UNAIDS, “Global AIDS update," in GARPR, 2016, pp. 1-12.

[9] IAS, "Global Fact Sheet: HIV/AIDS," in AIDS 2014 Stepping up the pace, 2014, pp. 1-20.

[10] M. N. Mignogna, S. Fedele, and L. lo Russo, "The World Cancer Report and the burden of oral cancer," Eur. J. Cancer Prev., vol. 13, no. 2, pp. 139-142, 2004.

[11] S. Warnakulasuriya, "Global epidemiology of oral and oropharyngeal cancer," Oral Oncol., vol. 45, no. 4-5, pp. 309-316, 2008 .

[12] B. Purgina, L. Pantanowitz, and R. R. Seethala, "A Review of Carcinomas Arising in the Head and Neck Region in HIVPositive Patients," Patholog. Res. Int., vol. 2011, p. Article ID 469150, 2011.

[13] E. N. Fedrizzi, J. K. Laureano, C. Schlup, M. O. Campos, and M. E. Menezes, "Human Papillomavirus ( HPV ) Infection in HIV Positive Women of Florianópolis, State of Santa Catarina, Brazil," J Bras Doencas Sex Tansm, vol. 23, no. 4, pp. 210-214, 2011.

[14] C. Queiroz, A. G. Travassos, E. Studart, J. Bouzas, and A. Filho, "Prevalence of Human Papilloma Virus in HIV-Positive and HIV-Negative Patients in the State of Bahia. A Pilot Study," The Brazillian journalofinfectiousdiseases, vol. 8, no. 5, pp. 356-362, 2004.

[15] M. Stevenson, F. Talavera, C. D. Braden, and G. D. Petruzzelli, "Head and Neck Cancer Staging TNM classification of Head and Neck cancer,"

http://emedicine.medscape.com/article/2007181?overview, 2017. [Online]. Available:

http://emedicine.medscape.com/article/2007181?overview. [Accessed: 14-Apr-2017].

[16] M. M. Gounder, R. D. Carvajal, J. Anand, C. D. Braden, and J. E. Harris, "Soft Tissue Sarcoma Staging," http://emedicine.medscape.com/article/2006584?overview, 2017.

[17] S. Marur and A. A. Forastiere, "Head and Neck Squamous Cell Carcinoma: Update on Epidemiology, Diagnosis, and Treatment," Mayo Clin. Proc., vol. 91, no. 3, pp. 386-396, 2016.

[18] A. Yakubu and O. Mabogunje, "Skin Cancer of the Head and Neck in Zaria, Nigeria," Acta Oncol. (Madr)., vol. 34, no. 4, pp. 469-471, 2017.

[19] O. B. Lilly-tariah, A. O. Somefun, and W. L. Adeyemo, "Current evidence on the burden of head and neck cancers in Nigeria," Head Neck Oncol., vol. 8, p. 1: 14, 2009.

[20] D. Gisselquist, R. Rothenberg, J. Potterat, and E. Drucker, "HIV infections in sub-Saharan Africa not explained by sexual or vertical transmission," Int. J. STD AIDS, vol. 13, pp. 657-666, 2002.

[21] F. Butt, M. L. Chindia, F. Rana, and F. Machingo, "Pattern of head and neck malignant neoplasms in HIV infected patients in Kenya," Int. J. Oral Maxillofac. Surg., vol. 10, pp. 907911, 2008.

[22] Uganda AIDS Commission, "The Uganda HIV and AIDS country progress report July 2015 - June 2016,” 2016. 
[23] A. Kamali, L. Mary, J. A. Grover, R. Pool, A. Ruberantwari, and A. Ojwiya, "Seven-year trends in HIV-1 infection rates, and changes in sexual behaviour, among adults in rural Uganda," AIDS, vol. 14, pp. 427-434, 2000.

[24] Uganda Ministry of Health and ICF Intetnational, "2011 Uganda AIDS Indicator Survey key findings," Calverton Maryland, 2012.

[25] E. Kakande, R. Byaruhaga, and A. Kamulegeya, "Head and neck squamous cell carcinoma in a Ugandan population: a descriptive epidemiological study," J Afr Cancer, vol. 2, pp. 219-225, 2010.

[26] E. Attar, S. Dey, A. Hablas, I. A. Seifeldin, M. Ramadan, L. S. Rozek, and A. S. Soliman, "Head and neck cancer in a developing country: A population-based perspective across 8 years," Oral Oncol., vol. 46, no. 8, pp. 591-596, 2010.

[27] L. Dobrossy, "Epidemiology of head and neck cancer: Magnitude of the problem," Cancer Metasasis Rev., vol. 24, pp. 9-17, 2005.

[28] UBOS, "Uganda Bureau of Statistics 2016, The National Population and Housing Census 2014 - Main Report, Kampala Uganda,” 2016.

[29] K. Hjelm and F. Atwine, "Health-care seeking behaviour among persons with diabetes in Uganda : an interview study," BMC Int. Health Hum. Rights, vol. 11, no. 1, p. 11, 2011.

[30] D. I. Conway, M. Petticrew, H. Marlborough, J. Berthiller, M. Hashibe, and L. M. D. Macpherson, "Socioeconomic inequalities and oral cancer risk: a systematic review and meta-analysis of case-control studies.," Int. J. Cancer, vol. 122, no. 12, pp. 2811-9, Jun. 2008.

[31] C. D. Llewellyn, N. W. Johnson, and K. a Warnakulasuriya, "Risk factors for squamous cell carcinoma of the oral cavity in young people--a comprehensive literature review.," Oral Oncol., vol. 37, no. 5, pp. 401-18, Jul. 2001.

[32] N. W. Johnson and S. Warnakulasuriya, "Global Oral Health Inequalities in Incidence and Outcomes for Oral Cancer: Causes and Solutions," Adv Dent Res, vol. 23, no. 2, pp. 237246, 2011.

[33] G. R. Kruse, D. R. Bangsberg, J. A. Hahn, E. Jessica, P. W. Hunt, C. Muzoora, J. P. Bennett, N. Jeffrey, and N. A. Rigotti, "Tobacco use among adults initiating treatment for HIV infectionin rural Uganda," AIDS Behav, vol. 18, no. 7, pp. 1381-1389, 2015.

[34] A. J. Christensen, P. J. Moran, S. L. Ehlers, K. Raichle, L. Karnell, and G. Funk, "Smoking and Drinking Behavior in Patients with Head and Neck Cancer: Effects of Behavioral Self-Blame and Perceived Control," J. Behav. Med., vol. 22, no. 5, pp. 407-408, 1999.

[35] JHU_CCP, "Alcohol Consumption in Uganda Literature Review March 2007,” Kampala, 2007.

[36] A. E. Coghill, P. A. Newcomb, M. M. Madeleine, B. A. Richardson, I. Mutyaba, F. Okuku, W. Phipps, H. Wabinga, J. Orem, and C. Casper, "Contribution of HIV infection to mortality among cancer patients in Uganda," AIDS, vol. 27, no. 18, pp. 2933-2942, 2015. 